\title{
Does alcohol cause hypertension or pseudo-hypertension?
}

\section{By D. G. Beevers and R. Maheswaran, University Department of Medicine, Dudley Road Hospital, Birmingham B18 7QH}

Most textbooks of medicine written since World War II do not mention alcohol as a cause of high blood pressure. Alcohol is, however, implicated in two books on hypertension published in the 1920s (Batty-Shaw, 1921; Halls Dally, 1926), presumably following the first report of an association by Lian (1915). Since the mid-1970s there has been increasing interest in this association which appears to be genuine. Many population studies have shown a close relation between blood pressure and alcohol intake and it is important to note that this is seen within the range of blood pressures conventionally considered to be normal and within the range of alcohol intakes normally regarded as moderate (Klatsky et al. 1977). There are now four clinical studies of hypertensive patients which show that reducing alcohol intake lowers blood pressure and restarting drinking raises pressure (Potter \& Beevers, 1984; Malhotra et al. 1985; Puddey et al. 1987; Veshima et al. 1987).

Whilst a causal association between alcohol and raised blood pressure may seem secure, it remains unproven whether alcohol causes the clinical syndrome of hypertension with its sequelae of heart attack, stroke, peripheral vascular disease, heart failure and renal damage. It does not necessarily follow that alcohol-induced rises in blood pressure carry the same grave prognosis as hypertension in general. Alcohol might cause instead a form of 'pseudo-hypertension' not associated with vascular disease.

Excessive alcohol intake is common and so is essential hypertension, and there will be occasions when these two conditions co-exist. It is difficult to anticipate how the clinician will be able to differentiate essential hypertension in a heavy drinker from alcoholinduced rises in blood pressure in an otherwise normotensive person. This paper discusses this problem and its possible implications.

\section{Epidemiological clues}

The most important population study to show a relation between alcohol and blood pressure is the Kaiser-Permanente project (Klatsky et al. 1977). Reliable blood pressure measurements and careful alcohol histories were taken in over 80000 men and women and the association was found to be independent of age, sex, ethnic origin, obesity, smoking habit and social class. However, this study also showed that the relation between alcohol and blood pressure was the same in previous heavy drinkers compared with those who were not previous heavy drinkers. Those who drank heavily in the past did not have high blood pressures if they now drank less. If heavy alcohol intake really causes hypertension then one would not expect it to be so reversible. In a more recent epidemiological study Maheswaran et al. (1987) have been able to confirm a correlation between blood pressure and alcohol intake measured by a $7 \mathrm{~d}$ alcohol diary, but this was largely accounted for by the alcohol intake in the $3 \mathrm{~d}$ immediately before blood pressure measurement and no relation was found with intakes in the days before that. This study, therefore, confirms the 'acuteness' of the alcohol-blood pressure relation, and also its reversibility. The Renfrew community study did, however, confirm an association between hypertension and high alcohol intake as judged by abnormalities of hepatic enzymes (Beevers, 1977), but this does not deny the possibility that at least some of the hypertensives who were also heavy drinkers might not have had 'real' hypertension. 


\section{Reversibility}

In a study of alcoholic patients admitted for detoxification a relation was found between blood pressure and the severity of alcohol withdrawal symptoms, as well as the amount of alcohol consumed in the previous 3 months (Saunders et al. 1981). However, no correlation was found with the estimated total lifetime alcohol intake. When the patients recovered from their alcohol withdrawal symptoms, blood pressures rapidly returned to normal and only rose again in those who subsequently restarted drinking. The quantities of alcohol consumed were enormous; one could argue that if alcohol causes hypertension, large quantities should cause even greater rises in blood pressure and this should be less reversible. But this was not the case.

All of the studies of alcohol consumption and discontinuation in hypertensive patients have reported blood pressure falls within $24 \mathrm{~h}$ to 1 week of reducing intake, and rises occurring equally rapidly on restarting (Potter \& Beevers, 1984; Malhotra et al. 1985; Puddey et al. 1987). Certainly the pressor effects of alcohol are rapid. Potter et al. $(1986 a, b)$ found that blood pressure rose and fell in close association with the blood alcohol levels, and there was no tendency for heavier drinkers to have a more prolonged pressor response to a fixed dose of alcohol.

We know of no other syndrome causing hypertension where blood pressure returns to normal so completely when the causative agent is withdrawn. In both phaeochromocytoma and primary aldosteronism it is usual for blood pressure to improve after surgery but some persistent hypertension commonly remains (Hamilton et al. 1953; Conn, 1963). In patients with renal artery stenosis, failure to normalize blood pressure is common and this failure is attributed to hypertension-induced damage of the contralateral kidney (McNeil \& Adelstein, 1975). Even in patients with childhood coarctation of the aorta, blood pressures are frequently not normalized by corrective surgery (Connihan, 1956). This may be because the raised pressure caused irreversible vasoconstriction with or without arteriolar thickening as well as damage to carotid baroreceptors. It appears that hypertension in these situations tends to set in motion a vicious cycle that perpetuates the elevation in blood pressure.

\section{Alcohol and stroke}

Epidemiological and clinical studies have demonstrated a close association between alcohol intake and stroke (Kozararevic et al. 1980; Gill et al. 1986). Whilst moderate intake may not be associated with stroke (and may even be protective) the consumption of more than an average of four units of alcohol daily (equivalent to 2 pints (approximately 1 litre) of British beer) is associated with an increased risk of stroke. Whilst stroke is very clearly a hypertension-related disease, it appears that the alcohol-stroke relation is independent of blood pressure (Gill et al. 1986). Alcohol may cause stroke by a direct constrictor effect on cerebral arteries (Altura et al. 1983) which is not necessarily related to the level of the blood pressure. The stroke and the elevation of blood pressure may share a common mechanism but may not be cause and effect.

\section{Coronary heart disease}

Most epidemiological studies have not found a positive association between alcohol consumption and coronary heart disease, apart from an excess of coronary disease in alcoholics (D'Alonzo \& Pell, 1968; Marmot, 1984). Indeed, moderate amounts of alcohol may protect against coronary heart disease, with a relative risk of 0.5 , although 
this suggestion remains controversial (Shaper et al. 1987). This cardioprotective effect may be due to elevated high-density-lipoprotein cholesterol levels caused by alcohol. There is a strong correlation between smoking and alcohol consumption (Gordon \& Doyle, 1986) which may contribute to the excess all-cause and cardiovascular mortality seen in very heavy drinkers. This association between smoking and alcohol might also be expected to increase the risk of heart disease in moderate drinkers, but this has not been the case in various studies.

Friedman et al. (1983) have attempted to see if alcohol-induced hypertension confers the same risk for cardiovascular disease as does hypertension brought about by other causes. They studied two groups of 850 patients each, matched for several factors, including systolic blood pressure. One group consumed three or more alcholic drinks daily while the other drank less than three, or none. The heavier drinkers had fewer admissions for coronary disease and the authors suggested that this was due to the cardioprotective effect of alcohol. Another interpretation is that alcohol-induced hypertension in the heavy drinkers simply did not carry the same risk for coronary heart disease as essential hypertension.

\section{Peripheral vascular disease}

We know of no association between alcohol intake and the aetiology or worsening of peripheral vascular disease. Indeed many clinicians recommend small quantities of alcohol to improve peripheral blood flow to the legs. As with coronary heart disease, the aetiology of peripheral vascular disease is multifactorial. If high-alcohol intake is an important cause of hypertension then an association between alcohol and claudication would be found.

\section{Renal failure}

Hypertension causes renal damage but we know of no association between alcohol and renal failure. We have investigated urinary albumin excretion rates in a general population and found no relation between it and reported alcohol intake (P. Gosling and D. G. Beevers, unpublished results).

\section{Heart failure}

Alcohol probably does cause a specific form of cardiomyopathy leading to congestive heart failure. In most cases blood pressure is normal or low due to a poor cardiac output (Brigden \& Robinson, 1964). Heart failure in hypertensive patients is, however, most often due to coronary artery disease, although left ventricular hypertrophy may be directly related to the height of the blood pressure. Left ventricular hypertrophy does not appear to be more common in heavy drinkers than in control subjects (D'Alonzo \& Pell, 1968).

\section{Blood pressure clinics}

Blood pressure clinic attenders do have a higher incidence of abnormalities of hepatic enzymes than normotensives (Beevers, 1977). This may well be because alcohol causes rises in blood pressure, but the evidence of hypertensive end-organ damage is poor. Some heavy drinkers would be expected to have essential hypertension with its cardiovascular consequences. There may be a significant minority of clinic attenders where cardiovascular risk is low, although the harmful consequences of heavy drinking are important. Clearly, alcohol reduction or abstention is the highest priority but antihypertensive drugs may not be necessary. An accurate history and clinical examination together with estimation of mean erythrocyte volume, serum $\gamma$-glutamyltransferase 
and uric acid levels may help to identify those heavy-drinking hypertensives who have no evidence of end-organ damage, and who may not need or benefit from antihypertensive drug therapy. They still need detailed counselling and remain clinically important as heavy drinking is a major hazard to health but by other mechanisms.

Epidemiologists have often felt that the relation between blood pressure and end-organ damage is imprecise and there has always been a search for subgroups of people who may not have a high vascular risk for a given level of blood pressure. We suggest that some heavy-drinking hypertensive patients represent just such a subgroup.

\section{REFERENCES}

Altura, B. M., Altura, B. T. \& Gebrewold, A. (1983). Science 220, 331-333.

Batty-Shaw, H. (1921). Hyperpiesia and Hyperpiesis. London: Henry Froude and Hodder and Stoughton.

Beevers, D. G. (1977). Lancet ii, 114-115.

Beevers, D. G., Zezulka, A. V., Potter, J. F., Bannan, L. T., Maheswaran, R. \& Gill, J. S. (1987). European Heart Journal 8, Suppl. B, 27-29.

Brigden, W. \& Robinson, J. (1964). British Medical Journal ii, 1283-1289.

Conn, J. W. (1963). Journal of the American Medical Association 183, 871-873.

Connihan, T. B. (1956). Clinical Science 15, 149-152.

D'Alonzo, C. A. \& Pell, S. (1968). Journal of Occupational Medicine 10, 344-350.

Friedman, G. D., Klatsky, A. L. \& Siegelaub, A. B. (1983). Annals of Internal Medicine 98, 846-849.

Gill, J. S., Zezulka, A. V., Shipley, M. J., Gill, S. K. \& Beevers, D. G. (1986). New England Journal of Medicine 315, 1041-1046.

Gordon, T. \& Doyle, J. T. (1986). Archives of Internal Medicine 146, 262-265.

Halls Dally, J. G. (1926). High Blood Pressure. London: William Heineman.

Hamilton, M., Lichfield, J. W., Peart, W. S. \& Sowry, G. S. C. (1953). British Heart Journal 15, $241-244$.

Klatsky, A. L., Friedman, G. D., Siegelaub, A. B. \& Gerard, M. J. (1977). New England Journal of Medicine 296, 1194-1200.

Kozararevic, D., Vojvodic, N., Dawber, T., McGree, D., Rasic, Z., Gordon, T. \& Zukel, W. (1980). Lancet i, 613-616.

Lian, C. (1915). Bulletin de l'Académie de Médecine 74, 525-528.

McNeil, B. J. \& Adelstein, S. J. (1975). New England Journal of Medicine 293, 221-225.

Maheswaran, R., Gill, J. S. \& Beevers, D. G. (1987). Clinical Science 72, Suppl. 16, 70 pp.

Malhotra, H., Mehta, S. R., Mathur, D. \& Khandelwal, P. D. (1985). Lancet i, 584-586.

Marmot, M. G. (1984). International Journal of Epidemiology 13, $160-167$.

Potter, J. F. \& Beevers, D. G. (1984). Lancet i, 119-122.

Potter, J. F., MacDonald, I. A. \& Beevers, D. G. (1986a). Journal of Hypertension 4, 435-444.

Potter, J. F., Watson, R. D. S., Skan, W. \& Beevers, D. G. (1986b). Hypertension 8, $625-631$.

Puddey, I. B., Beilin, L. J. \& Vandongen, R. (1987). Lancet 1, 647-651.

Saunders, J. B., Beevers, D. G. \& Paton, A. (1981). Lancet ii, 653-656.

Shaper, A. G., Phillips, A. N., Pocock, S. J. \& Walker, M. (1987). British Medical Journal 294, $733-737$.

Veshima, H., Ogihara, T., Baba, S., Tabuchi, Y., Mikawa, K., Hashizume, K., Mandai, T., Ozawa, H., Kumahara, Y., Asakura, S. \& Hisanari, M. (1987). Journal of Human Hypertension 1, 113-119. 